\title{
WestVirginiaUniversity
}

THE RESEARCH REPOSITORY @ WVU

Graduate Theses, Dissertations, and Problem Reports

1998

\section{Identification of math anxiety subtypes}

Aline Elizabeth Rabalais

West Virginia University

Follow this and additional works at: https://researchrepository.wvu.edu/etd

\section{Recommended Citation}

Rabalais, Aline Elizabeth, "Identification of math anxiety subtypes" (1998). Graduate Theses,

Dissertations, and Problem Reports. 836.

https://researchrepository.wvu.edu/etd/836

This Thesis is protected by copyright and/or related rights. It has been brought to you by the The Research Repository @ WVU with permission from the rights-holder(s). You are free to use this Thesis in any way that is permitted by the copyright and related rights legislation that applies to your use. For other uses you must obtain permission from the rights-holder(s) directly, unless additional rights are indicated by a Creative Commons license in the record and/ or on the work itself. This Thesis has been accepted for inclusion in WVU Graduate Theses, Dissertations, and Problem Reports collection by an authorized administrator of The Research Repository @ WVU. For more information, please contact researchrepository@mail.wvu.edu. 


\title{
Identification of Math Anxiety Subtypes
}

\author{
Aline Rabalais \\ of West Virginia University in partial \\ fulfillment of the requirements for the degree of \\ Master of Arts \\ in \\ Clinical Psychology \\ Daniel W. McNeil, Ph.D., Chair \\ Stanley H. Cohen, Ph.D. \\ Philip N. Chase, Ph.D. \\ December 8, 1998 \\ Morgantown, West Virginia
}

Thesis submitted to the Eberly College of Arts and Sciences

Keywords: Mathematics, Anxiety, Cluster Analysis, Instructional Set 


\title{
Identification of Math Anxiety Subtypes
}

\author{
Aline E. Rabalais
}

\begin{abstract}
Conceptualizations of mathematics anxiety, as well as factors that are empirically related to it, were identified from the existing literature. These factors are test, evaluation, trait, and state anxiety, as well as gender and level of math ability. Differences in these factors were hypothesized to distinguish subtypes of highly math anxious individuals from one another. In order to determine whether subtypes exist, cluster analyses were performed on a sample of 96 highly math anxious college students. The results revealed three clusters distinguished by completion time on two versions of a math test and age. Furthermore, participants' responses on a variety of self-report questionnaires, as well as performance on a math test, were assessed under stressful versus relaxing testing conditions. Stressful testing conditions produced a decrement in math test performance, and also resulted in an increase in state anxiety level, particularly for women. The obtained results supported the existence of math anxious subtypes; they also suggested that level of anxiety can be manipulated by instructions in a math testing setting.
\end{abstract}




\section{Acknowledgments}

I would like to express my sincerest thanks to Dan McNeil for supervising this project through the many stages of its completion. His valuable feedback and willingness to devote time and effort toward its progress have allowed for the refinement of this document. I also want to thank Stan Cohen for providing multiple recommendations with respect to the data analyses, and Phil Chase who helped with the initial conceptualization, and who made suggestions for polishing the final document. All of their efforts were crucial to the successful completion of this thesis and are recognized with sincere appreciation.

Special thanks are extended to Joseph Scotti, my colleague and friend, who served as my "thesis cheerleader" and source of emotional support over the years. Dr. Scotti has helped me with many of the fine details of this project, such as allowing me access to undergraduate students in his posttraumatic stress laboratory who helped collect data, and assisting me in the submission of the final document to the university, as well as numerous offers of assistance of which I did not take advantage. I also want to express my gratitude to Derek Hopko for his contribution in terms of discussing conceptual dilemmas and running subjects, and I want to thank the various undergraduate students who helped enter and collect data.

Also, my sincerest thanks to my husband, Jason Akerman, and my family, Opal Rabalais, Michael Rabalais, and Shawnee Rabalais for their unwavering support through many trying times during all stages of this project. They listened patiently to many long monologues about my frustrations and successes with regard to this thesis. Their support was crucial to the completion of this project. Their love, belief in my abilities, and their willingness to express those sentiments have perhaps been the greatest contribution to my success. 


\section{Table of Contents}

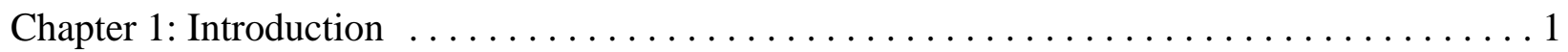

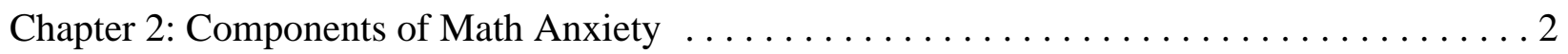

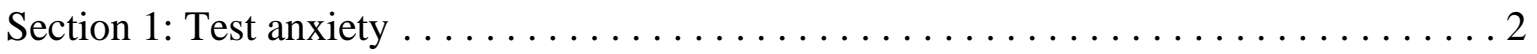

Section 2 : Trait anxiety and state anxiety $\ldots \ldots \ldots \ldots \ldots \ldots \ldots \ldots \ldots \ldots \ldots \ldots \ldots \ldots \ldots$

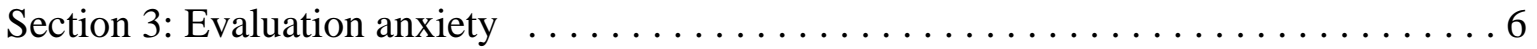

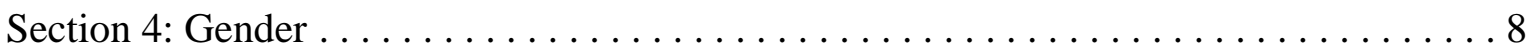

Section 5: Math skill and math performance $\ldots \ldots \ldots \ldots \ldots \ldots \ldots \ldots$

Section 6: Math anxiety and math performance $\ldots \ldots \ldots \ldots \ldots \ldots \ldots \ldots$

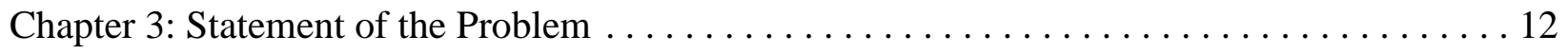

Section 1: Limitations of the current literature $\ldots \ldots \ldots \ldots \ldots \ldots \ldots \ldots \ldots \ldots \ldots \ldots$

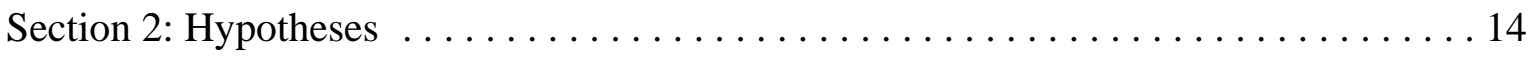

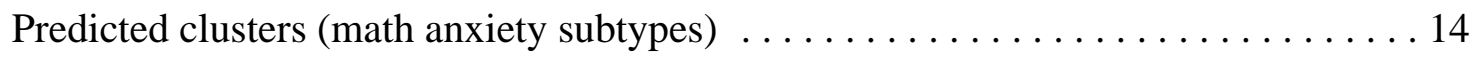

Influence of stressful and relaxing instructions $\ldots \ldots \ldots \ldots \ldots \ldots \ldots \ldots$

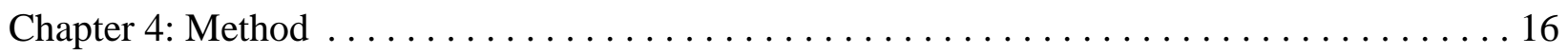

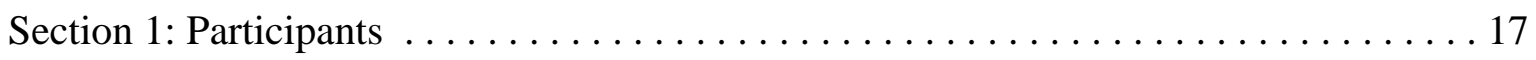

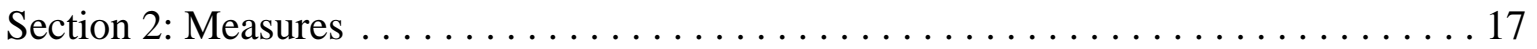

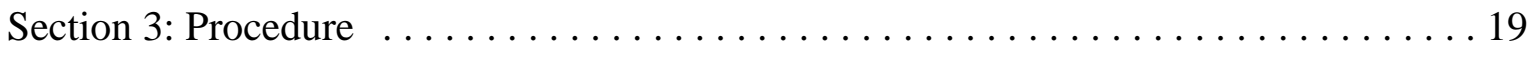

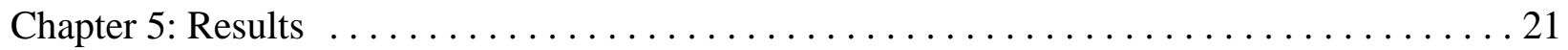

Section 1: Selection of highly math anxious sample $\ldots \ldots \ldots \ldots \ldots \ldots \ldots \ldots \ldots$

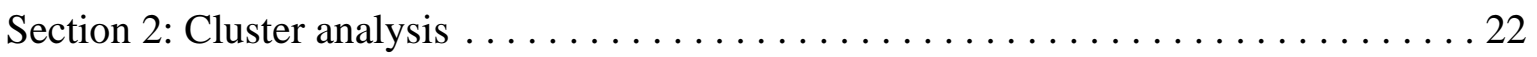

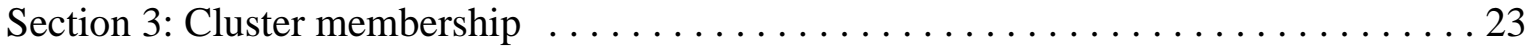

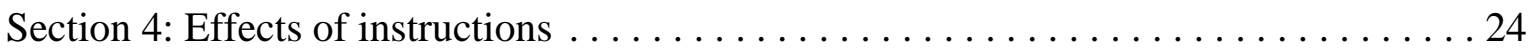

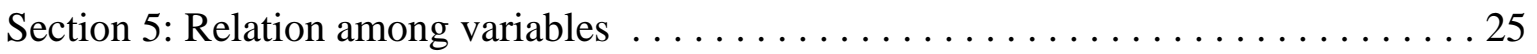

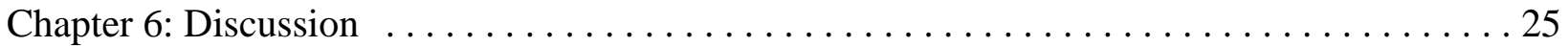

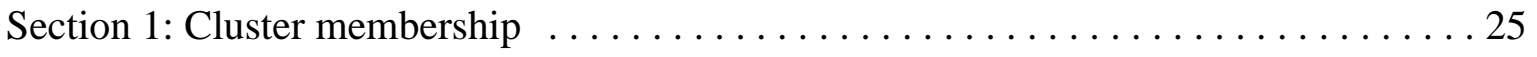

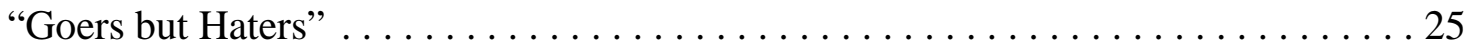

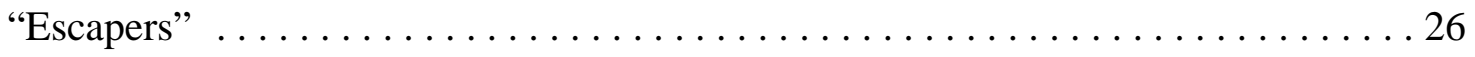




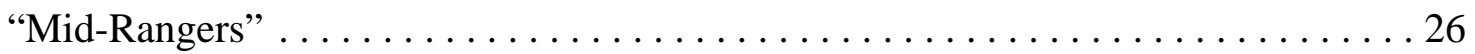

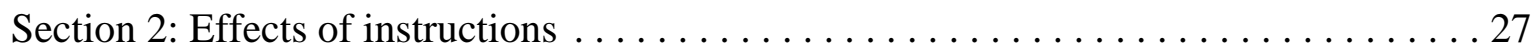

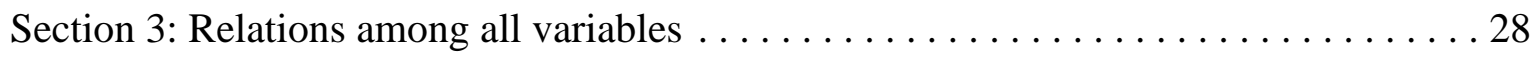

Section 4: Limitations and future directions $\ldots \ldots \ldots \ldots \ldots \ldots \ldots \ldots \ldots \ldots \ldots \ldots \ldots$

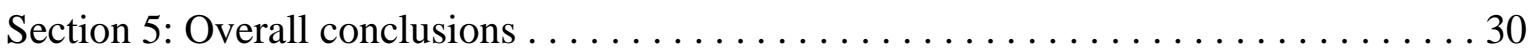

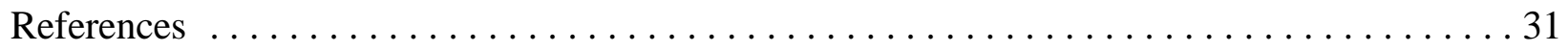

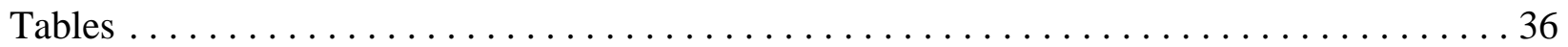

Appendices ............................................ 41

Appendix A: Demographics Questionnaire - Part $1 \ldots \ldots \ldots \ldots \ldots \ldots \ldots \ldots 1$

Appendix B: Demographics Questionnaire - Part 2 ................... 43

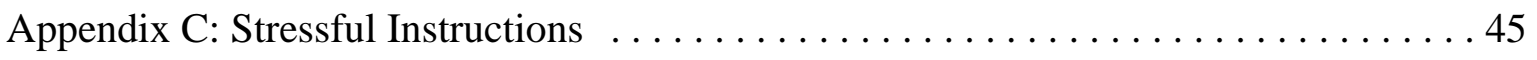

Appendix D: Relaxing Instructions $\ldots \ldots \ldots \ldots \ldots \ldots \ldots \ldots \ldots \ldots \ldots \ldots$

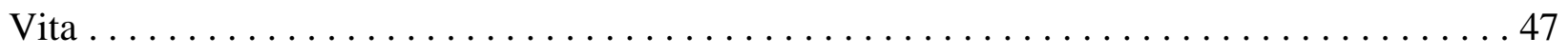




\section{List of Tables}

Table 1: Variables within Each of Six Hypothesized Clusters of Math Anxious

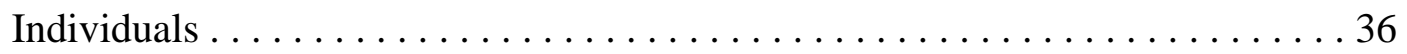

Table 2: Description of the Four Groupings of Participants $\ldots \ldots \ldots \ldots \ldots \ldots \ldots$

Table 3: Means, (Standard Deviations), and ANOVA Results for Variables

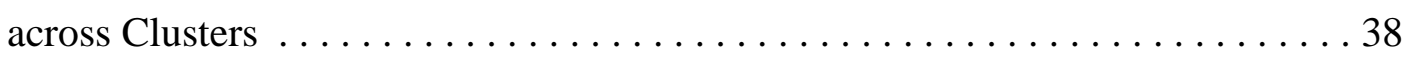

Table 4: Pearson Correlations among Dependent Measures used in Cluster Analyses . . . 39

Table 5: Differences between Actual Cluster Solutions $\ldots \ldots \ldots \ldots \ldots \ldots \ldots$ 


\section{Chapter 1: INTRODUCTION}

The psychological literature provides a number of conceptualizations of mathematics anxiety. Kennedy and Tipps (1990) define math anxiety as a fearful, negative, emotional reaction to mathematics. Tobias and Weissbrod (1980) refer to math anxiety as "the panic, helplessness, paralysis, and mental disorganization that arises among some people when they are required to solve a mathematical problem" (p. 65). Furthermore, Fennema and Sherman (1976) describe math-related distress as being accompanied by bodily symptoms (e.g., increased heart rate). Hendel and Davis (1978) conceptualize mathematics anxiety as an affective response that includes avoidance of math, subsequent failure to learn basic math skills, and thus negative career and school-related decisions. Finally, Richardson and Suinn (1972) provide a widely accepted definition of math anxiety as "feelings of tension and anxiety that interfere with the manipulation of numbers and the solving of mathematical problems in a wide variety of ordinary life and academic situations" (p. 551).

Mathematics anxiety may also be analyzed using a three-systems approach, which includes the dimensions of physiology, self-report, and overt behavior (e.g., Lang, 1968). For instance, math anxiety may be indexed by increases in heart rate and skin conductance. Math-related anxiety might also be defined as reports of statements such as "I don't have enough time to finish this test" or "I can't do this problem." Finally, math anxiety can be viewed as a set of overt behaviors such as trembling, or, as mentioned by Hendel and Davis (1978), avoidance of situations that require one to perform math-related tasks.

From a behavior analytic perspective, math anxiety can be viewed as including both overt (i.e., observable) and covert (i.e., unobservable) behavior. For instance, excessive psychomotor activity, time spent off-task, avoidance, and distressed verbalizations are examples of possible overt math anxious behaviors. Examples of math anxious covert behaviors are physiological reactions, thoughts, and emotional responses. From a behavior analytic perspective, behavior is a function of the relations among responses and consequences. For example, a person may respond 
to a math exam in a college class with a number of negative behaviors (e.g., off-task behaviors, such as looking out of the window) that contribute to the consequence of poor test performance. Furthermore, environmental cues, such as the presence of a teacher and students waiting for their tests, may often precede the off-task-poor-performance contingency. In the future, these cues will serve as discriminative stimuli which signal that there is a high probability that the off-task-poorperformance contingency will occur. Thereafter, the individual may not attend the math class, thus avoiding the unpleasant physical sensations and poor performance associated with math exams. More globally, individuals with high math anxiety are likely to avoid careers (e.g., chemistry, banking, engineering) that require them to manipulate numbers and use mathematics skills.

\section{Chapter 2: COMPONENTS OF MATH ANXIETY}

\section{$\underline{\text { Relationship between Math and Test Anxiety }}$}

There has been debate over whether math anxiety is a specific phobia of math-related material or whether it reflects general test anxiety experienced across a variety of subject areas. Ramirez and Dockweiler (1987) briefly mention opinions on both sides of this issue. Meece, Parsons, Kaczala, Goff, and Futterman (1982) state that some critics propose that math anxiety primarily reflects fear associated with a variety of testing situations. A study conducted by Brush (1978) did not support this contention. Brush's results revealed that physical science, social science, and humanities majors showed no group differences in level of test anxiety, which was measured by the Suinn Test Anxiety Behavior Scale (STABS; Suinn, 1969); however, differences in math anxiety levels, as measured by the Mathematics Anxiety Rating Scale (MARS; Richardson \& Suinn, 1972), were found. Physical science majors exhibited the lowest levels of math anxiety, followed by social science, then humanities majors. From these results, Brush concluded that it is possible to measure anxiety about math beyond that which is associated with tests in general. In view of the findings reported in the literature, Ramirez and Dockweiler (1987) concluded that for some students, math anxiety reflects a generalized fear of failing tests, while for others, it represents a math-specific, affective response. An implication 
that can be drawn from this assertion is that math anxiety is multifaceted across individuals.

Richardson and Woolfolk (1980) propose that math anxiety is a distinctive form of test anxiety. Although both math and test anxiety share the feature of performance fear, the two constructs are not equivalent. One difference between the two types of anxiety is that math anxiety possibly includes negative emotional reactions to perceived societal views about one's math test performance as well as to problem-solving activities themselves. For example, math performance may be perceived as an indicator of one's intelligence, degree of masculinity, and wisdom. According to Richardson and Woolfolk, the extreme nature of such connotations may contribute to increased levels of debilitating anxiety. Furthermore, highly math anxious people may have a specific fear of manipulating numbers as opposed to words or concepts (e.g., philosophical issues in the study of history) outside of mathematical inquiry.

\section{$\underline{\text { Conclusions }}$}

Although investigators have made suggestions about the relationship between math and test anxiety, no consensus has been reached. Some researchers propose that general test anxiety accounts almost totally for math anxiety (e.g., Meece et al., 1982), while others contend that the two types of anxiety can be distinguished from one another (e.g., Brush, 1978). Another suggestion is that math anxiety is a subtype of test anxiety (e.g., Richardson \& Woolfolk, 1980). Finally, math anxiety has been described as multifaceted (e.g., Ramirez \& Dockweiler, 1987).

The multifaceted conceptualization may provide the most comprehensive explanation for the relationship between math anxiety and test anxiety. It is hypothesized that if a person exhibits distressed behavior across testing situations, then poor performance on math exams may reflect high levels of general test anxiety. If a person experiences anxiety and performs poorly only in math-related situations, then he or she may have a situation-specific problem. In summary, general test anxiety may or may not coexist with math anxiety, and both types of anxiety can occur in isolation. 


\section{$\underline{\text { Trait and State Anxiety }}$}

Spielberger and Vagg (1995) refer to trait anxiety as "relatively stable individual differences in anxiety proneness" (p. 6). State anxiety is conceptualized as a transitory affective state that varies in intensity and frequency over time (Spielberger, 1972a). Spielberger (1972b) describes test anxiety as a situation-specific form of trait anxiety. In support of this relationship, Spielberger (1983) demonstrated that measures of individual differences in trait anxiety predicted that subjects would experience state anxiety when put in stressful, evaluative, testing situations. Also, Spielberger (1980) found that test anxious students were generally higher in trait anxiety and tended to perceive exams as more threatening than those with low trait anxiety.

Similar to Spielberger's (1972b) conceptualization of test anxiety, Anton and Klisch (1995) suggest that math anxiety may be regarded as a "situation-specific personality trait" (p. 98). These authors hypothesize that a person's tendency to perceive math-related situations as threatening may be a function of his or her level of trait anxiety. In support of this idea, there are several studies showing correlations among measures of state, trait, and math anxiety (e.g., Plake, Ansorge, Parker, \& Lowry, 1982; Plake \& Parker, 1982; Plake, Smith, \& Damsteegt, 1981). For instance, Betz (1978) demonstrated that introductory psychology students' scores on a modified version of the Mathematics Anxiety Scale (MAS; Fennema \& Sherman, 1976) were significantly and negatively correlated $(\underline{r}=-.28)$ with scores on the Trait scale of the State-Trait Anxiety Inventory (STAI; Spielberger, Gorsuch, \& Lushene, 1970). Thus, the higher the math anxiety level, which is indicated by lower MAS scores, the higher the level of trait anxiety. Betz (1978) also found moderate correlations $(\underline{r}=-.42)$ between lower MAS scores and higher levels of test anxiety on the Test Anxiety Inventory (TAI; Spielberger, 1980).

Examining the results provided by Fennema and Sherman (1976) and Betz (1978), it is speculated that the lower correlation between math anxiety and trait anxiety as compared to the apparently higher correlation between math anxiety and test anxiety may be accounted for by the degree of similarity in the types of environments referred to in questionnaire items. Specifically, TAI items may assess test anxiety, and MAS items may assess test anxiety and/or math anxiety; 
thus, there is a possible confound, which may raise the correlational value. In contrast, STAITrait items assess anxiety across a wider variety of settings, which in turn, may produce a lower correlational value as compared to that found between the MAS and TAI.

\section{Conclusions}

Both test and math anxiety have been conceptualized as situation-specific forms of trait anxiety (Anton \& Klisch, 1995; Spielberger, 1972b). It is theorized that people high in trait anxiety are more likely to view the evaluative component of taking exams as stressful; thus, trait anxiety is expressed within a specific context (i.e., during exams). In contrast, for highly math anxious individuals, trait anxiety is expressed within situations that involve the manipulation of numbers. Furthermore, trait anxiety is believed to be an enduring, innate, personality characteristic (Anton \& Klisch, 1995; Spielberger \& Vagg, 1995).

There are several limitations to the state-trait theory of math and test anxiety. A general finding within the literature is that there are correlations among measures of math, test, and trait anxiety, indicating that as levels of math anxiety rise, so do levels of test anxiety and trait anxiety. Such results do little to either distinguish math anxiety from test anxiety or to establish that they are both subsumed under a unitary concept. Also, these results do not necessarily support the proposition that math anxiety and test anxiety are symptoms of underlying trait anxiety. Given the inherent difficulty of measuring these constructs, as well as the limitations of drawing conclusions from correlational studies, more research needs to be conducted.

Instead of viewing math and test anxiety as subtypes of innate, trait anxiety, an alternative hypothesis is that high trait anxiety reflects a learning history characterized by the reinforcement and generalization of anxious reactions across a variety of situations. Such learning processes might account for the correlations found between test and trait anxiety. Similarly, positive correlations between scores on indices of math, state, and trait anxiety may suggest that anxious reactions have generalized to many settings, including math-related ones. Again, some people with high math anxiety will have high trait anxiety and others will not, depending on their 
individual learning histories.

\section{Evaluation Anxiety}

\section{Relationship to Math Anxiety}

Studies have revealed significant, positive correlations between measures of evaluation anxiety and mathematics anxiety. In a sample of women enrolled in a mathematics anxiety program, Hendel (1980) demonstrated such a correlation $(\underline{r}=.48)$ between math anxiety levels, as measured by the MARS (Richardson \& Suinn, 1972), and scores on Watson and Friend's (1969) Fear of Negative Evaluation (FNE) scale. Similarly, Rounds and Hendel (1980) conducted a factor-analytic study that revealed a positive correlation $(\underline{r}=.36)$ between a Numerical Anxiety factor of the MARS and FNE scores.

Studies have suggested that there is a relation between general test anxiety and evaluation anxiety. For instance, Mandler and Sarason (1952) found, when given instructions that emphasized that participants' abilities would be evaluated, high test anxious people performed more poorly on a block design test than did low anxious subjects. Trends in the data also revealed that while the evaluation-oriented instructions detrimentally affected the performance of high anxious subjects, they facilitated the performance of the low anxious group.

These trends are consistent with Yerkes and Dodson's (1908) theory of the relation between arousal and performance. They proposed that there is an inverted, $\mathrm{U}$ - shaped relation between arousal and performance; that is, moderate levels of arousal facilitate performance, while extremely low or high levels interfere with it. Perhaps individuals who are not highly test anxious experience facilitating anxiety when given evaluation-oriented instructions, thus their test performance is improved. In contrast, people who are highly test anxious may perform poorly as a result of anxiety-provoking instructions, which presumably increase physiological arousal (e.g., heart rate and respiration rate). In addition to type of instructions, other factors might influence one's anxiety level (e.g., timed testing, insufficient time to complete the work). 
One factor that has been shown to influence the inverted $U$ relation is task difficulty. In fact, the Yerkes-Dodson theory was modified to take task difficulty into consideration (Broadhurst, 1959). Based on the results of empirical studies, the modification stated that the more difficult a task, the lower the level of arousal required to acquire optimum performance. This modification has implications for math anxiety and performance. That is, high levels of anxiety may be more likely to depress math performance on difficult tasks as compared to moderate or easy ones. This conclusion, however, is based on an assumption that arousal can be equated with anxiety. These constructs (i.e., anxiety and arousal) are related and overlapping, but are not necessarily the same. Consequently, one must be cautious in drawing conclusions about anxiety based on an arousal model.

Gender may be another factor that influences level of evaluation anxiety. There is evidence that females react more negatively to evaluation-related, environmental cues than do men. In a study conducted by Arch (1987), subjects were told that their performance on a computer task would be used to determine their professional potential. Relative to males, females responded to this testing situation with higher discomfort, and greater decreases in willingness to return for further evaluations.

\section{$\underline{\text { Conclusions }}$}

Although investigators have demonstrated positive correlations among evaluation, test, and math anxiety (e.g., Hendel, 1980; Mandler \& Sarason, 1952; Richardson \& Suinn, 1972), the nature of such relations is unclear. To clarify what these correlations represent, it may be helpful to determine the conditions under which evaluative fears are likely to occur. For instance, fear of negative evaluation (e.g., fear of being given low grades or being considered unintelligent by an authority figure) may be associated with all testing situations or just with math-related ones. Another finding that merits further investigation is that women react more negatively to evaluative situations than do men (Arch, 1987), thus suggesting that gender is a relevant variable. In summary, further investigations, which focus on the specific testing conditions that provoke anxiety in men versus women, need to be conducted in order to provide a more comprehensive 
picture of math anxiety.

\section{$\underline{\text { Gender }}$}

The literature demonstrates that, in general, females have higher levels of math anxiety and males have lower ones. Alexander and Martray (1989) created a 25-item, abbreviated version of Richardson and Suinn's (1972) MARS. Using this instrument with a sample of 517 college students, these authors found that female respondents reported higher levels of math anxiety than did their male counterparts. Marsh (1988) also found higher levels of math anxiety in females than in males. In another study, Betz (1978) modified the MAS (Fennema \& Sherman, 1976) and administered it to 652 college students. The results of the investigation revealed that women reported significantly higher levels of math anxiety than did males. Finally, a meta-analytic investigation of 152 studies conducted by Hembree (1990) again indicated that females display higher levels of math anxiety and males lower levels.

One possible antecedent for this gender difference is that parental expectations of their children may translate into boys and girls receiving differing messages concerning their ability to succeed in math. Entwisle and Baker (1983) found that parents expected their sons to be better at math than their daughters; however, in general, they did not find differences between math grades for male versus female children. Entwisle and Baker interpreted their results as showing that parental opinions affected their children's expectations for successful math performance. Parsons, Adler, and Kaczala (1982) found that parents estimated that their daughters had to work harder than their sons to do well in math. Also, parents of sons thought that advanced math was more important for their child than did the parents of daughters. Furthermore, the results of a path analysis suggested that children's math self-concepts were more directly related to parental expectations than to the children's own past performances in math.

A meta-analysis conducted by Hyde, Fennema, and Lamon (1990) produced results relevant to gender differences in the math test performance of children. The study revealed that girls outperformed boys in elementary and junior high in the areas of understanding mathematical 
concepts, complex problem solving, and computation; however, no gender differences in basic problem solving were shown. In contrast, differences favoring men in basic problem solving emerged at the high school and college levels. One hypothesis for this shift in performance is that young children have less opportunity to actively avoid math experiences as a result of parental influences, thus their skill level is not detrimentally affected. Although differences in the expectations for success exist between male versus female children and their parents at the elementary and junior high levels, these students are typically taught basic math skills in school, and are not encouraged to pursue individualized study plans. However, in high school and college, parental influences may influence choice of course work and exposure to math, thus affecting math skill and performance level. Another possibility is that differences emerge during the high school years because it is a time when children are learning to adopt the gender roles prescribed by society; therefore, biases favoring the importance of math skills for men versus women may affect course selection, level of motivation exerted in those classes, and subsequently, math performance.

\section{$\underline{\text { Conclusions }}$}

Perhaps parental opinions are based on the belief that women cannot or should not excel in math because doing so would be nonfeminine (Eccles, 1987). As a result of such possible biases, Eccles hypothesizes that parents may subtly or overtly discourage their daughters from taking math courses (e.g., by saying "you will not need that class when you become a mother" or by preventing the child from taking the class). The result might be to create a skills deficit due to lack of exposure to math courses and to raise the level of fear associated with math-related material. Furthermore, parental expectancies may impact children's willingness to enroll in math courses, the result being less exposure to, and thus, less competency in the area of mathematics. All of these factors may then influence females' choice of career as adults, as well as their subsequent math-related experiences. In turn, negative, math-related experiences may partially explain the higher levels of math anxiety exhibited by women. Further studies might be conducted to determine whether or not gender role factors influence future math exposure and performance. 


\section{Influence of Mathematics Skill Level on Math Performance}

A number of investigators have suggested that poor performance and high anxiety level are primarily due to lack of mathematics skill. For instance, Hunsley and Flessati (1988) suggested that math anxiety is a function of poor math preparation and experiences. For example, a student may avoid math classes because he fears manipulating numbers. In turn, when he takes a mathematics achievement test, he lacks the knowledge needed to perform adequately, and he fails, thus making him more likely to be anxious under similar testing situations in the future. In support of this hypothesis, these authors found that compared to nonanxious college students, highly math anxious students with high MARS scores reported lower math grades, more negative math-related experiences, and more negative attitudes towards mathematics in high school on a Math Biography questionnaire. Using MARS scores to categorize participants into groups, Ashcraft and Faust (1994) found that a high math anxious group was the least accurate in completing addition and multiplication tables, a medium anxiety group was the slowest, and a low anxiety group was the most rapid and accurate. They suggested that these findings possibly reflected group differences with respect to level of mathematical expertise and exposure to formal mathematics.

One hypothesis is that if low level of skill is the primary cause of poor math performance, then treatments which reduce math anxiety will not necessarily improve math test scores. A study by Schneider and Nevid (1993) may support this hypothesis. In this investigation, a group that received systematic desensitization showed a reduction in math anxiety over the course of treatment. The systematic desensitization treatment group, however, did not differ significantly from a delayed treatment group on a measure of math aptitude. The results of this study suggest that reducing anxiety alone is not sufficient for improving math performance; thus, it is possible that the predominant cause of poor performance is skills deficits rather than elevated anxiety level.

\section{$\underline{\text { Conclusions }}$}


The literature supporting the hypothesis that lack of skill is the primary cause of poor math performance (e.g., Ashcraft \& Faust, 1994; Hunsley \& Flessati, 1988; Lalonde \& Gardner, 1993) has limitations. One problem is that many studies have examined differences between low and high math anxious groups using math course grades as dependent variables (e.g., Hunsley \& Flessati, 1988). When results indicate that high math anxious individuals report low math grades, it is often assumed that low skill level is the cause of poor math performance. This conclusion is overstated, however, given that grades reflect level of skill confounded with math anxiety. Similar limitations are present in studies that use math skills test scores as indicators of math ability. In spite of this confound, course grades and tests are important measures of math skills level; thus, they should not be abandoned. Instead, limitations should be addressed, and the experimental results should be stated in terms of approximated level of math skill.

\section{Influence of Anxiety Level on Performance}

\section{Math Anxiety, General Test Anxiety, and Skill Level}

In contrast to the hypothesis that poor performance is a function of skill level alone, it is possible that high anxiety level itself (i.e., irrespective of skill level) can detrimentally affect test scores. For example, Bander, Russell, and Zamostny (1982) conducted a study that revealed that from posttreatment to follow-up, cue-controlled relaxation was found to be superior to study skills training in improving math performance, which was assessed via the Differential Aptitude Test (DAT; Bennett, Seashore, \& Wesman, 1959). Similarly, relaxation was superior to study skills with respect to lowering MARS scores. Also, Hembree (1988) reviewed the test anxiety literature and concluded that general test anxiety, rather than skills deficits, accounted for lowered test performance. Specifically, it was demonstrated through a meta-analysis that systematic desensitization interventions improved grade point average, and that both systematic desensitization and relaxation procedures improved test performance. This meta-analysis provided information about the effect of particular treatments on general test performance, yet it did not specify the effect of those treatments on math performance. Another meta-analysis conducted by Hembree (1990) however, did conclude that behavioral treatments (e.g., systematic desensitization) produce improvements in college math test scores; thus, the study supported the 
idea that reducing anxiety level will positively influence math performance.

\section{$\underline{\text { Conclusions }}$}

Currently, some studies indicate that poor math performance is a function of low skill level (e.g., Ashcraft \& Faust, 1994), while others suggest that poor math performance is a result of elevated anxiety level (e.g., Hembree, 1990). Given the discrepancies in the literature, further treatment studies would be helpful in determining whether skill or anxiety level is the primary determinant of math performance. If such investigations were to reveal improvements, the argument that anxiety level itself can affect math performance would be supported. Conversely, if performance did not improve, the hypothesis that math skill level is primary would be strengthened.

\section{Chapter 3: STATEMENT OF THE PROBLEM}

\section{Limitations of the Current Literature}

Although there are theoretical explanations for the relation between anxiety and performance, several limitations need to be addressed. The Yerkes-Dodson theory (Broadhurst, 1959; Yerkes \& Dodson, 1908) proposes an inverted U-shaped relation between performance and arousal. Extending this theory, a similar relation may exist between anxiety and performance; that is, extremely high and low math anxious individuals perform worse than people having midlevel anxiety. A limitation of this theory, however, is that it assumes that all individuals have the same skill level, and that anxiety is the main determinant of performance (e.g., math performance). In actuality, it is possible that there are several subtypes of math anxious individuals. For example, some people may have mid-level anxiety, which is assumed to be optimal for performing well, yet lack math skills, and thus perform poorly on math tests. Such individuals would not conform to the U-shaped distribution theorized by the Yerkes-Dodson law. Similarly, individuals who have extremely high levels of anxiety, yet perform well on math tests would not conform to the U-shaped distribution proposed by the Yerkes-Dodson law. Again, the relation between anxiety and arousal is an imperfect one, so all implications of the Yerkes- 
Dodson model may not apply to anxiety.

In addition to theoretical limitations, there are problems in the empirical literature that need to be addressed. There are many studies demonstrating significant correlations between math anxiety and particular variables (i.e., test, evaluation, state, and trait anxiety, gender, and level of math skill or performance). A limitation is that correlations do not imply causal relationships between variables. Furthermore, measurement-related confounds make such relations difficult to uncover. For instance, it is assumed that math skill can be measured via math achievement tests, although test anxiety may be a confounding variable. Another limitation in the current body of research is that many studies examine correlations between math anxiety and only a few variables within one group of people (e.g., between math anxiety and trait anxiety in a college student sample). In such studies, an implicit assumption is that math anxiety is consistently related to a given variable (e.g., trait anxiety) across individuals, irrespective of the potential influence of other factors. A way to address this problem might be to conduct studies that examine correlations among a greater number of factors (e.g., test anxiety, evaluation anxiety, gender, and age), rather than between only two or three variables of interest.

An alternative approach to analyzing math anxiety is to identify several correlated variables within subtypes (i.e., clusters) of math anxious individuals. Math anxious subtypes may include some, but not necessarily all, of the possible components of math anxiety (e.g., math skill, levels of trait and test anxiety, and level of fear of negative evaluation). An assumption of the subtype model is that there are clusters that represent specific groups of people. The existence of clusters would suggest that math anxiety is not a unitary concept, but instead is multifaceted across individuals.

The current study had several purposes. The first goal was to determine whether or not subtypes of math anxious individuals exist. To answer this question, participants in this study were administered questionnaires that assessed several variables of interest: test anxiety, fear of negative evaluation, math anxiety, state and trait anxiety, and performance on two versions of a 
math achievement test. Responses on these questionnaires, as well as data collected on several other variables (e.g., age, gender, and achievement test completion times) were utilized in a variety of analyses, including cluster analyses. The resultant clusters represented subtypes of math anxiety.

Another goal was to examine how performance on the math achievement test was affected by a stressful versus a non-stressful testing environment. Specifically, the stressful environment included test-related instructions that attempted to provoke a high level of evaluation anxiety, while the nonstressful testing environment included instructions that encouraged relaxation and discouraged evaluative concerns.

\section{Hypotheses}

\section{$\underline{\text { Predicted Clusters }}$}

Given the four primary variables that were examined in the current study, there are numerous possible subtypes (i.e., clusters) that may have been distinguishable. From that range of possibilities, six hypothesized clusters were identified. These six clusters were based on data from the previously outlined empirical literature. Specifically, studies have demonstrated correlations between variables such as math performance, math anxiety, test anxiety, state and trait anxiety, evaluation anxiety, and demographic variables, such as gender. Previous studies have not, however, examined whether these variables comprise subtypes of individuals; therefore, the current investigation was exploratory in nature, and thus not intended to be an extensive examination of all possible clusters. Table 1 lists variables predicted to be included within each hypothesized cluster.

When deciding how to describe clusters, a heuristic rule was applied based on four overlapping anxiety levels, which range from the most general to the most specific. The most general level is trait anxiety (i.e., extends across settings and may or may not include test anxiety and/or math anxiety). Next is evaluation anxiety, which also extends across situations, but has a more discrete response pattern. The next level is test anxiety (i.e., more situation-specific and 
may or may not include math anxiety). The final level is math anxiety (i.e., most specific), which may be more akin to a specific math-related phobia. The more general levels were assumed to be confounded with more specific levels. For instance, people with high trait anxiety may have test anxiety, or math anxiety, or all three types of anxiety; thus, these people were described with an emphasis on trait anxiety, given the impossibility of ruling out the other two types of anxiety. In summary, the assumption was that it is preferable to describe a subtype in terms of the most general level of anxiety rather than the most specific in order to avoid making an error in the direction of being too exclusive. However, there are limitations to this rule for describing clusters. For instance, a person may have high trait anxiety and high math anxiety yet low test anxiety, and thus be described as trait anxious without taking into account low test anxiety. A cluster of such individuals would be counter to the implicit assumption that test anxiety is the middle level, and thus is necessarily present. Such an error is preferable, however, to describing people in the cluster as being highly math anxious without accounting for general elevations in anxiety across situations.

It is important to remember that all of the individuals entered in the cluster analyses were chosen using an elevated MARS-R score as the criterion, thus their scores on the other measures may also be higher than the scores of people not included in the analyses. Given this selection criterion, when the words "higher" or "lower" are used to describe test anxiety, trait anxiety, evaluation anxiety, and math performance, it is important to remember that these terms are used to compare highly anxious individuals within one cluster to other highly anxious individuals within a different cluster.

\section{Clusters 1 and 2}

Cluster 1 represents an individual whose poor performance may be the cause or the consequence of trait anxiety. Additionally, this individual is likely to display avoidance behaviors, thus exacerbating performance deficits. Similarly, participants in Cluster 2 are trait anxious, yet their math performance may be higher than that of Cluster 1, given that they display fewer avoidance behaviors. Given that studies have demonstrated positive correlations among 
indices of state anxiety, trait anxiety, and math anxiety (e.g., Betz, 1978; Plake \& Parker, 1982), it is possible that Clusters 1 and 2 exist.

\section{$\underline{\text { Clusters } 3 \text { and } 4}$}

Cluster 3 includes individuals who are highly test anxious. For such people, high anxiety and avoidance behaviors result in depressed performance on a variety of tests, including math-related ones. People in Cluster 4 also have a high level of test anxiety, which may contribute to poor performance; however, Cluster 4 people perform better because they display fewer avoidance behaviors. These two clusters were hypothesized after examining the results of investigations that revealed positive correlations among measures of test anxiety, evaluation anxiety, and math anxiety (e.g., Hendel, 1980; Mandler \& Sarason, 1952).

\section{$\underline{\text { Clusters } 5 \text { and } 6}$}

Finally, Cluster 5 includes individuals who have a math-specific anxiety, which possibly interacts with avoidance behaviors to depress math performance. Similarly, Cluster 6 is comprised of people who have a math-specific anxiety, yet who perform better than those in Cluster 5 due to fewer avoidance behaviors. Clusters 5 and 6 were conceptualized based on Ramirez and Dockweiler's (1987) proposition that for some people, math anxiety represents a math-specific, affective response.

\section{Influence of Instruction Type}

Another prediction was that participants who were presented with stressful instructions before taking a measure of math performance, a mathematics subtest of the Scholastic Achievement Test (SAT; available from the Educational Testing Service, Princeton, NJ), would perform worse on it than those who received relaxing instructions before the SAT. That is, it was predicted that there would be a main effect for type of instruction. It was hypothesized that the stressful instructions would raise participants' level of anxiety, thus resulting in more mistakes on the SAT. These hypotheses were plausible given the aforementioned results reported by Mandler and Sarason (1952). It was hypothesized that women's level of math anxiety would be 
higher and men's lower, thus corroborating the findings presented in the literature. Finally, significant positive correlations were expected among the various self-reports of anxiety, and negative correlations were anticipated between math anxiety and math performance measures.

\section{Chapter 4: METHOD}

\section{$\underline{\text { Participants }}$}

Undergraduate college student volunteers enrolled in introductory psychology classes at West Virginia University (WVU) were the participants. Of the 547 students who were entered into the study, 59 individuals dropped out after completing only one of two testing sessions, thus leaving a pool of 488 people. Students signed informed consent statements before they were involved in the investigation. Volunteers were then given a series of questionnaires including the Revised Math Anxiety Rating Scale (MARS-R; Plake \& Parker, 1982), a measure of math anxiety. In all, 187 males, 299 females, and 2 participants who did not indicate their gender participated in both testing sessions. In return for participation, all volunteers received extra credit in their psychology course.

\section{$\underline{\text { Measures }}$}

The MARS-R (Plake \& Parker, 1982) is a 24-item version of Richardson and Suinn's (1972) original 98-item MARS. (Alexander and Martray [1989] also have a revised 25-item version of the original MARS, but it was not used in this study.) Each item is rated on a scale of 1 (low anxiety) to 5 (high anxiety). Higher total scores reflect greater levels of math anxiety. The MARS-R is useful because it is relatively short, and it has shown good internal reliability and a significant, positive correlation (i.e., $\underline{r}=.97$ ) with the full MARS (Richardson \& Suinn, 1972). Two factors have been identified within the MARS-R: Learning Mathematics Anxiety (LMA) and Mathematics Evaluation Anxiety (MEA). The LMA factor reflects items that pertain to the process of studying math, while the MEA factor includes statements about math-related testing situations. Plake and Parker (1982) assessed validity of the MARS-R relative to the external criterion of math achievement using the Mathematics Achievement Test (MAT; American 
College Testing Program, 1976), and found a correlation coefficient of $-.45(\underline{p}<.01)$ between the MARS-R and the MAT.

Level of test anxiety was measured using the TAI (Spielberger, 1980; Spielberger et al., 1978). This instrument consists of 20 statements pertaining to test-related reactions (e.g., "during a course examination I get so nervous that I forget facts I really know"). One is asked to respond to these statements by indicating the frequency with which he or she has experienced a given reaction using a 4-point scale: 1 (almost never), 2 (sometimes), 3 (often), or 4 (almost always). The TAI also contains two subscales: worry and emotionality. Higher overall TAI score as well as higher subscale scores reflect higher levels of test anxiety. TAI total and subscale scores have been demonstrated to possess good internal consistency as evidenced by high alpha reliability coefficients using three college student samples (i.e., total scores in the .94 to .95 range, worry subscale scores in the .86 to .91 range, and emotionality subscale scores in the .89 to .91 range). TAI total scores also show high, positive correlations with other measures of test anxiety, and low to moderate, negative correlations with grade point average (GPA; Spielberger et al., 1978).

The STAI (Spielberger et al., 1983), which consists of two subscales (i.e., State and Trait), was also administered. The trait scale assesses how one feels in general, while the state scale examines how one feels at the moment. When completing the Trait scale, responses are made in terms of frequency of anxious feelings; responses can range from 1 (almost never) to 4 (almost always). On the state form, the respondents answer in terms of the intensity of their feelings; scores range from 1 (not at all) to 4 (very much so). Higher scores on both the State and Trait scales indicate greater anxiety. In general, the STAI is psychometrically sound. For the Trait scale, test-retest reliability is relatively high. For both forms, the alpha coefficients are high, and concurrent validity is also reasonable (Spielberger et al., 1983).

Participants also completed the FNE (Watson \& Friend, 1969). The FNE consists of 30 truefalse items that cover a variety of situations in which one might be concerned about being 
evaluated. These items consist of self-referential statements that respondents either rate as true or false. Items that are answered in a way that indicates a high level of evaluation anxiety are considered "critical items," and are summed to produce a total FNE score. The higher the number of critical items endorsed, the higher the level of evaluation anxiety. The FNE is a useful measure of evaluation anxiety given its sound psychometric properties and availability of historical comparative data (McNeil, Ries, \& Turk, 1995).

Demographic and historical variables were assessed via a form that was constructed by the investigators. The variables assessed were as follows: gender, age, ethnicity, number of years of math course work, overall GPA in high school and college, math courses and grades in college and high school, and level of math courses (i.e., advanced, standard, or remedial). These forms are in Appendices A and B.

Finally, a subtest of the SAT (available from the Educational Testing Service, Princeton, NJ) provided a measure of mathematics ability. The SAT was chosen because it is supported by normative, statistical data, and it has good psychometric properties, including high test-retest reliability (i.e., in the .80 to .90 range), and correlation coefficients in the .40 range for women, and in the .30 range for men (Robinson, 1983). Although other entrance tests have also been shown to be predictive of college grades, the SAT was chosen because of the availability of different versions, the large base of national normative data, and its multiple-choice format, which allowed for ease of scoring.

Within the SAT, there are three math sections. The math sections test knowledge of geometry, fractions, algebra, division, inequalities, and basic statistical concepts. Typically, there is a section that tests math skills using a standard 25-item, multiple choice format. A second section tests these skills using a 10-item, multiple choice format. Lastly, a third section includes 25 items and tests math skills via quantitative comparisons and a free-response format. In this study, only the 25-item, multiple choice section from both the 1995 SAT and 1996 SAT was administered. This section was chosen over the free-response format section because it could 
more easily be scored. Furthermore, it was chosen over the 10-item multiple choice section in order to allow more exposure time for anxiety induction.

\section{Procedure}

All 488 students participated in two sessions, separated by one week. A number of these paired sessions were made available to participants across the Fall 1997 semester. Approximately one-half of the sessions had stressful instructions followed by relaxing instructions, and the other half were in the opposite order. For a summary of the experimental groups within sessions one and two, see Table 2.

During the first week, participants completed the following assessment instruments in the order indicated: demographics questionnaire, MARS-R, STAI-State, STAI-Trait, TAI, and FNE. After completing these instruments, participants were exposed to either stressful (high anxiety situation) or relaxing instructions (low anxiety situation) that were based on those utilized by Smith, Michael, and Hocevar (1990). See Appendices C and D for the instructions. After receiving instructions, participants again completed the state portion of the STAI. Because the STAI-State was conceptualized and developed as a measure of current distress to be used across a variety of settings, it was repeated in order to assess the influence of instructions on anxiety level. Participants then took a math subtest of either a SAT administered in November of 1995 or a SAT administered in May of 1996.

A minimum of two, and a maximum of three, experimenters were present during each testing session. Testing took place in standard WVU classrooms located on the University's main campus. The number of people present during a testing session ranged from approximately 7 to 60 participants. The SAT completion time for each participant was recorded for each administration using a stopwatch.

Several aspects of the testing situation were manipulated in order to induce or reduce anxiety. In the high anxiety situation, after providing participants with test instructions, the 
experimenters walked around the room observing students. As they walked, the stopwatches used to record completion times were prominently displayed either in their hands or hanging around their necks. They were also instructed to display serious, grim facial expressions, and to wear professional attire (e.g., blazer and slacks for men, and suits or dresses for women). During this condition, participants were allowed 30 minutes to complete the SAT. Also, anxiety-provoking verbal prompts were periodically provided to the group as a whole. The following prompts were given at 10, 20, 25, and 30 minutes, respectively: "Remember, evaluation of your mathematical ability will be determined by this test, "Remember, you must be accurate as well as quick," "You only have five minutes left. Be quick and accurate," and "Please stop and put your pencils down."

Testing characteristics were also manipulated during the low anxiety situation. Experimenters were instructed to stand stationary at the front of the classroom after testing instructions were given. Also, experimenters were instructed to display relaxed facial expressions, and to wear casual attire (e.g., jeans and T-shirts). Due to limitations in the amount of time available to use the scheduled testing rooms, participants were actually given 90 minutes to finish the SAT; however, they were told they had as much time as they desired (i.e., implying more than 90 minutes if needed) in order to reduce the potential stress of having a time limit. No participants requested more than 90 minutes to complete the test. The following relaxing verbal prompts were provided to the group as a whole at 10,20, 25, and 90 minutes, respectively: "Remember, relax and enjoy the experience of working these challenging, yet fun problems," "Remember to complete the test, but don't rush. Relax and take your time," "You have worked for a while now. Please continue to work at the most comfortable pace for you," and "Please stop and put your pencils down."

In the second week, each participant received the alternate set of instructions and version of the SAT. Participants again completed the state portion of the STAI both before and directly after receiving instructions, but they did not complete the other assessment instruments that were previously mentioned. The aforementioned procedures for administering the SAT were again 
followed.

\section{Chapter 5: RESULTS}

\section{Selection of a Highly Math Anxious Sample}

A subsample of 96 high math anxious individuals was chosen from the total sample of 488 participants. In order to yield a sufficient number of people to enter into the analyses (i.e., $\underline{\mathrm{n}}=$ 96), participants were chosen from the highest $20 \%$ of people with elevated MARS-R scores. No significant difference was found in the MARS-R scores of males $(\underline{\mathrm{M}}=54.3, \underline{\mathrm{SD}}=17.2)$ and females $(\underline{\mathrm{M}}=56.4, \underline{\mathrm{SD}}=17.1)$ in the total sample, $\underline{\mathrm{t}}(484)=1.34, \underline{\mathrm{p}}=.179$. A total of 36 males and 60 females was included in the subsample, however, maintaining the relative percentage of males and females in the subsample as in the total sample. The majority (i.e., 91.4\%) of the subsample were Caucasian ( $\underline{n}=85), 5.2 \%(\underline{n}=5)$ were African American, $3 \%(\underline{n}=3)$ were Hispanic, Asian/Pacific Islander, or American Indian/Alaska Native, and three individuals did not report their ethnicity.

Other criteria were also used to choose the subsample. Analysis of the total sample yielded a significant difference between scores on the $1995(\underline{\mathrm{M}}=10.5, \underline{\mathrm{SD}}=4.0)$ and $1996(\underline{\mathrm{M}}=11.4, \underline{\mathrm{SD}}$ $=4.3$ ) versions of the SAT subtest, indicating that participants were more successful in answering items on the 1996 version, $\underline{\mathrm{t}}(457)=5.81, \underline{\mathrm{p}}<.01$. Given this difference, approximately equal numbers of people receiving the 1996 version first as compared to those receiving the 1995 version first were included in the subsample. Similarly, equal numbers of people were selected from those who received the two different types of instruction order (i.e., stressful first and relaxing second or relaxing first and stressful second).

\section{Cluster Analysis}

Participants were analyzed using a cluster analytic procedure. Cluster analysis is a statistical procedure which is used to group individuals who are similar to one another with respect to designated variables of interest. The clustering procedure utilized in this study was Ward's 
Method, which allowed production of a dendrogram of overlapping, hierarchical clusters. Additionally, a measure of distance between cases within a cluster must be specified. Squared Euclidean distance was the measure of distance utilized, given that it is commonly used in conjunction with Ward's method. Ward's method was chosen because it produces clusters of approximately equal size, thus allowing for appropriate examination using analyses of variance (ANOVAs). Also, Ward's Method was chosen over alternatives because it produces replicable cluster solutions. Monte Carlo studies have been used to simulate data sets that exist in reality (e.g., personality type data produced from psychometrically sound assessment instruments). A variety of simulated data sets are then subjected to clustering methods. Methods that consistently produce the same cluster solution are said to provide adequate recovery of known cluster structure. There is evidence that Ward's method provides such consistent recovery (Aldenderfer \& Blashfield, 1984).

\section{Cluster Membership}

A series of hierarchical cluster analyses using Ward's Method was conducted. These analyses specified 5, 4, 3, and 2 cluster solutions using squared Euclidean distance as the measure of distance. Typically, clusters including fewer than 15 participants are not considered theoretically or statistically meaningful. The 5 cluster solution produced two clusters with fewer than 15 participants (i.e., a cluster of 8 and a cluster of 1), and the 4 cluster solution produced clusters with 29,38, and 28 participants as well as a cluster with one participant, respectively; thus, neither of these solutions were appropriate. The 3 cluster solution, however, yielded clusters of approximately equal size (i.e., 30, 38, and 28 participants), while the 2 cluster solution produced two clusters of 30 and 66 participants. Given that the 3 cluster solution produced distinctive clusters of approximately equal size (i.e., 30, 38, and 28 persons) and did not include clusters with fewer than 15 participants, it was chosen as the most appropriate solution for this data set.

Additionally, one-way ANOVAs were conducted to determine if clusters differed from one another with respect to the dependent variables entered into the cluster analyses. The dependent 
measures examined were age, STAI-Trait score, TAI score, FNE score, MARS-R score, time (in minutes) taken to complete the 1995 version of the SAT, time taken to complete the 1996 version of the SAT, the difference between the total scores of the first and the second STAI-State administered within the same testing session for the 1995 and the 1996 versions of the SAT, and the total number of correct responses to the 1995 version and to the 1996 version of the SAT. Given that the 1995 version was more difficult than the 1996 version (i.e., as indicated by a ttest), there was no attempt to collapse across SAT version. Instead, SAT scores of each version were entered separately into the cluster analyses in order to determine whether or not difficulty of the task distinguished math anxious subtypes. Also, due to a large amount of missing data, responses on the demographics questionnaire, other than gender and age, were not analyzed. A Chi-square test was conducted on number of males and females in each cluster and revealed no significant differences, $X^{2}(2, \underline{\mathrm{N}}=96)=2.19, \underline{\mathrm{p}}=.335$.

The results of these one-way ANOVAs and follow-up Tukey Honestly Significant Difference Tests (HSD) produced several significant differences among the three clusters. See Table 3 for a summary of cluster means, standard deviations, and test statistics. Mean completion time (minutes) for both the 1995 and 1996 versions of the SAT differed significantly among all three clusters. Similarly, significant differences in mean completion time for the 1996 version of the SAT were found for all three cluster comparisons. A significant difference in age was found between cluster 1 and cluster 2. Finally, the there was an overall effect for scores (i.e., number correct) on the 1996 version of the SAT, $\underline{F}(2,95)=3.1, \underline{p}=.048$. However, Tukey HSD tests revealed no significant differences among the 1996 SAT scores of the three clusters.

\section{Effects of Instructions}

A three-way ANOVA was conducted on Gender (i.e., male or female) x Order of Instructions (i.e., either relaxing first and stressful second, or stressful first and relaxing second) x Type of Instructions (i.e., either stressful or relaxing) on the 96 highly math anxious participants' STAI-State change scores. The results revealed that the Gender x Type of Instruction interaction was significant, $\underline{\mathrm{F}}(1,92)=7.61, \underline{\mathrm{p}}<.007$. Follow-up Tukey HSD tests at 
the .05 level revealed that females' STAI-State change scores were significantly higher under stressful conditions $(\underline{\mathrm{M}}=5.7, \underline{\mathrm{SD}}=8.1)$ than under relaxing conditions $(\underline{\mathrm{M}}=-4.1, \underline{\mathrm{SD}}=9.8)$. Additionally, a significant main effect was found for Type of Instruction, $\underline{\mathrm{F}}(1,92)=21.11, \underline{\mathrm{p}}<$ .0001. Specifically, it was discovered that change scores were greater under stressful instructions $(\underline{\mathrm{M}}=3.9, \underline{\mathrm{SD}}=8.2)$ than under relaxing instructions $(\underline{\mathrm{M}}=-3.2, \underline{\mathrm{SD}}=9.3)$. Specifically, state anxiety increased as a result of receiving stressful instructions and decreased as a result of receiving relaxing instructions. No other interactions or main effects were significant.

A three-way ANOVA was conducted on Gender x Order of Instructions (i.e., either relaxing first and stressful second, or stressful first and relaxing second) x Type of Instruction (i.e., SAT under relaxing instructions or stressful instructions) on SAT scores (i.e., number of correct items). The results revealed that only the Order of Instructions x Type of Instruction interaction was significant, $\underline{F}(1,92)=13.76, \underline{p}<.001$. Tukey HSD follow-up tests at the .05 level revealed that if participants received stressful instructions during session two, they performed more poorly $(\underline{\mathrm{M}}=8.6, \underline{\mathrm{SD}}=3.1)$ than if they received relaxing instructions during session two $(\underline{\mathrm{M}}=9.8, \underline{\mathrm{SD}}$ =3.7). Also, if participants received stressful instructions first, they scored higher $(\underline{\mathrm{M}}=9.9, \underline{\mathrm{SD}}=$ 3.5) than if they received stressful instructions during session two. Mean SAT score of participants who received relaxing instructions during session one $(\underline{\mathrm{M}}=8.9, \underline{\mathrm{SD}}=3.3)$ did not differ significantly from those of any other cell. No other interactions or main effects were significant.

\section{$\underline{\text { Relation Among All Variables }}$}

Correlations among all the dependent variables used in the cluster analyses were also examined as shown in Table 4. Low, significant, positive correlations were found between MARS-R and FNE total scores, as well as between MARS-R and TAI total scores, suggesting that when math anxiety is high, so is test anxiety and evaluation anxiety. Moderate, significant, positive correlations were found between FNE total scores, TAI total scores, and STAI-Trait total scores, as well as between TAI total scores and STAI-Trait total scores. These results suggest that when evaluation anxiety is high, so is test anxiety and trait anxiety. Finally, low, negative 
correlations were found between MARS-R total scores and SAT scores for both the 1995 and the 1996 version; thus, performance scores are low when math anxiety is high. These relations corroborate those found in the math anxiety literature.

\section{Chapter 6: DISCUSSION}

\section{$\underline{\text { Cluster Membership }}$}

\section{Cluster 1- "Goers but Haters"}

The cluster analysis employed in this study suggests that there are three subtypes of highly math anxious individuals who attend college, as shown in Table 5. Although none of the anxiety questionnaire variables (i.e., test anxiety, trait anxiety, evaluation anxiety, or math performance) in the hypothesized clusters distinguished the actual clusters that were found, there was a parallel with respect to implied escape level. Cluster 1 is represented by a relatively older individual who is less escapist than younger math anxious individuals in the other two clusters. Individuals in this cluster are labeled "goers but haters," a term coined by Milgrom and colleagues (1980) to describe highly dental anxious people who are not avoidant. Relative lower escape level is indicated by greater test-taking times on both the 1995 and 1996 versions of the SAT. This cluster is most similar to hypothesized clusters 2,4 , and 6 , which were assumed to include higher math performance scores as a result of fewer escape behaviors (e.g., leaving the test early).

\section{Cluster 2 - "Escapers"}

Individuals in Cluster 2, designated "escapers," were most similar to those in hypothesized clusters 1, 3, and 5. People in Cluster 2 demonstrated the least time taken to complete the SAT, thus perhaps indicating the highest level of escape behaviors. These individuals were also the youngest in age.

\section{$\underline{\text { Cluster } 3 \text { - "Mid-Rangers" }}$}

Cluster 3 was not similar to any of the hypothesized clusters. The individuals in this cluster were designated "mid-rangers" because they displayed higher levels of escape behavior (as 
implied by lower SAT completion times) than those people in Cluster 1, yet lower levels of escape behavior than those in Cluster 2. Also, in terms of age, these individuals were in between those in the other clusters.

Several implications may be drawn from the results of this study. It appears that variables such as level of test anxiety, trait anxiety, and evaluation anxiety do not typically distinguish among clusters of high math anxious individuals. Furthermore, the analyses revealed only a three cluster solution, yet six were hypothesized. These results showed, however, that the amount of time taken to complete the SAT as well as age distinguished the three clusters. These findings tentatively suggest that math anxiety may be less multifaceted than predicted, although still not a unitary phenomenon.

Although the analyses produced a limited number of subtypes, it is possible that there are unmeasured variables that may potentially distinguish math anxious individuals from one another. In the current study, differences with respect to completion time were found, perhaps suggesting differential levels of math-related escape behavior. This interpretation of completion time is tentative, however, given that shorter completion time may, in some cases, reflect a high level of math skill rather than a high level of escape behavior. The overall ANOVA differences, with the "Escapers" groups having the poorest performance, however, are not consistent with such a hypothesis. Furthermore, the results suggest that older students may display fewer escape behaviors than younger ones. Given that completion time and age were two variables that distinguished the clusters, yet were not hypothesized to be influential, it is possible that there are other facets to math anxiety than predicted. Further investigations that utilize cluster analyses may reveal other important variables that discriminate math anxious individuals from one another.

\section{Effects of Instructions}

Results support the prediction that stressful instructions produce a decrease in math performance as compared to relaxing instructions. For instance, individuals who received 
stressful instructions during session two performed worse on the SAT than participants who received relaxing instructions during session two. The order (i.e., stressful first and relaxing second or relaxing first and stressful second) in which participants received the two types of instructions also appears to be important. Participants who received stressful instructions first scored higher on the SAT than people who received stressful instructions during session two. Perhaps this finding reflects a contrast effect. That is, participants who received relaxing instructions during the first session may have been impacted more strongly by the change to negative (i.e., stressful) instructions during the second session. Their anxiety likely increased in session two, thus depressing math performance.

ANOVA results may also have implications for gender differences with respect to changes in STAI-State scores within a testing session. When collapsing across gender, a main effect for type of instruction was found; that is, changes in STAI-State scores were greater under the stressful condition as compared to those under the relaxing condition. When grouping by gender, however, a significant difference was found between the STAI-State change scores of females receiving stressful instructions versus the STAI-State change scores of females receiving relaxing instructions. A similar effect of instructions on STAI-State change scores was not found with males, suggesting that women may be more sensitive to stressful demand characteristics present within testing situations.

\section{$\underline{\text { Relations Among all Variables }}$}

In general, there were positive relations among the various measures of anxiety utilized in this study, and there were negative relations among the anxiety measures and math performance. From these data, it is evident that increases in one type of anxiety (e.g., math anxiety) are likely to accompany increases in other types of anxiety (e.g., evaluation anxiety). These relations corroborate findings cited in the literature (e.g., Betz, 1978; Hendel, 1980), indicating a positive, low to moderate relation among measures of anxiety. Similarly, the negative relation between math performance and elevated anxiety level found in this study is similar to the negative, low to moderate relations reported in the psychological literature (e.g., Hunsley \& Flessati, 1988). 


\section{$\underline{\text { Limitations and Future Directions }}$}

First of all, some variables that were entered into the cluster analyses were not included in the hypothesized clusters (e.g., completion time on the SAT). Also, the hypothesized clusters did not take into account the possibility of mid-level scores on the variables of interest, and not all theoretical clusters were represented in the hypotheses.

Often, cluster analytic studies employ cross-validation techniques, such as dividing the sample and conducting cluster procedures on both halves in order to ensure that similar results are generated. Given the limited number of highly math anxious individuals in the sample, it was not possible to employ this technique. Another procedure that is often used is the comparison of the results of several clustering methods to verify that a given cluster solution is consistently generated. Ideally, this cluster solution would be compared to those solutions presented in the literature; however, there is no body of evidence suggesting that a particular cluster solution of math anxious people has been consistently found. As a result of this paucity of information, it is unclear what a comparison of cluster solutions would add to the findings of this study. Instead, it is suggested that a future direction for math anxiety research is to conduct further cluster analytic studies in order to provide evidence for or against the three cluster solution presented in this investigation.

Future studies might also investigate whether or not the inclusion of less anxious individuals would affect cluster membership. By studying a wider range of anxious individuals, more subtypes might be identified (e.g., low math anxious individuals who perform poorly on math tests and low math anxious people who perform well on math tests). Once well-defined clusters are identified, the next step may be to design new treatments or to apply existing treatments to particular subtypes. For instance, a cluster of people having a math-specific phobia and who perform poorly only on math tests might benefit from a combination of math skills training and exposure to stressful, math-related testing situations. On the other hand, a group of people having generalized test anxiety, and who perform poorly on all tests, including math exams, may need 
exposure to a wider variety of testing situations. Such studies would help to clarify some of the issues surrounding math anxiety (e.g., whether or not it is a multifaceted problem), and they might speed the development of innovative treatments for a problem that plagues students of many educational levels, as well as people seeking to work in various professions.

Another consideration that deserves further investigation is the possible influence of testing situation characteristics. For instance, manipulation of math problems under timed pressure may influence the speed of responding as well as the quality of performance irrespective of skill level. Or, perhaps timed pressure increases level of anxiety, which then depresses math performance. These possible relations might be addressed in future studies.

\section{$\underline{\text { Overall Conclusions }}$}

In summary, this study provides tentative support for the existence of three subtypes among highly math anxious college students. These subtypes include a group of younger individuals who may engage in significant escape behaviors, a group of somewhat older students who may display somewhat fewer escape behaviors, and a group of slightly older individuals who may engage in significantly fewer escape behaviors. Again, caution should be exercised when interpreting completion time in terms of escape behaviors, given that in some cases, it might reflect level of math skill. Furthermore, this study demonstrated that instructional set has an effect on anxiety level. Because this study was exploratory in nature, however, more research needs to be conducted in order to confirm the existence of math anxiety subtypes.

The identification of highly math anxious subtypes may encourage the application of particular types of treatments to specific problems. For instance, escapist subtypes may be treated using exposure-based strategies (e.g., relaxation training, desensitization, or flooding to mathrelated stimuli) along with math skills training. In contrast, a treatment for nonescapers might emphasize math skills training with less of a focus on coping techniques. Furthermore, the identification of highly math anxious subtypes might encourage preventative strategies. For instance, revealing subtypes of highly math anxious children might guide educators' efforts to 
remediate specific math skills, and to implement relaxation and exposure-based treatments before a child experiences academic failure in the area of mathematics. Identification of such subtypes is a first step toward tailoring treatment protocols to particular individuals. 


\section{References}

Aldenderfer, M. S., \& Blashfield, R. K. (1984). Cluster analysis. Beverly Hills, California: Sage Publications.

Alexander, L., \& Martray, C. (1989). The development of an abbreviated version of the Mathematics Rating Scale. Measurement and Evaluation in Counseling and Development, 22. 143-150.

American College Testing Program (1976). College Mathematics Placement Program Examinations. Iowa City, Iowa: Author.

Anton, W. D., \& Klisch, M. C. (1995). Perspectives on mathematics anxiety and test anxiety. In C. D. Spielberger \& P. R. Vagg (Eds.), Test anxiety: Theory, assessment, and treatment (pp. 93-106). Washington, DC: Taylor \& Francis.

Arch, E. (1987). Differential responses of females and males to evaluative stress: Anxiety, self-esteem, efficacy and willingness to participate. In R. Schwarzer, H. M. Ploeg, \& C. D. Spielberger (Eds.), Advances in test anxiety research (Vol. 5, pp. 97-106). Hillsdale, NJ: Erlbaum Associates.

Ashcraft, M. H., \& Faust, M. W. (1994). Mathematics anxiety and mental arithmetic performance: An exploratory investigation. Cognition and Motivation, 8, 97-125.

Bander, R. S., Russell, R. K., \& Zamostny, K. P. (1982). A comparison of cue-controlled relaxation and study skills counseling in the treatment of mathematics anxiety. Journal of Educational Psychology, 74, 96-103.

Bennett, G. K., Seashore, H. G., \& Wesman, A. G. (1959). A manual for differential aptitude tests. New York: Psychological Corporation.

Betz, N. E. (1978). Prevalence, distribution, and correlates of mathematics anxiety in college students. Journal of Counseling Psychology, 25, 441-448.

Broadhurst, P. L. (1959). The interaction of task difficulty and motivation: The Yerkes Dodson law revised. Acta-Psychologica, 16, 321-338.

Brush, L. R. (1978). A validation study of the Mathematics Anxiety Rating Scale (MARS). Educational and Psychological Measurement, 38, 485-490.

Eccles, J. S. (1987). Gender roles and women's achievement-related decisions. Psychology 
of Women Quarterly, 11, 135-170.

Educational Testing Service (1995, November). Scholastic Achievement Test. (Available from the Educational Testing Service, P.O. Box 6200, Princeton, NJ, 08541-6200).

Educational Testing Service (1996, May). Scholastic Achievement Test. (Available from the Educational Testing Service, P.O. Box 6200, Princeton, NJ, 08541-6200).

Entwisle, D. E., \& Baker, D. P. (1983). Gender and young children's expectations for performance in arithmetic. Developmental Psychology, 19, 200-209.

Fennema, E., \& Sherman, J. (1976). Fennema-Sherman Mathematics Attitudes Scales: Instruments designed to measure attitudes toward the learning of mathematics by males and females. JSA Catalog of Selected Documents in Psychology, 6, 31. (Ms. No 1225).

Hembree, R. (1988). Correlates, causes, effects and treatment of test anxiety. Review of Educational Research, 58, 47-77.

Hembree, R. (1990). The nature, effects, and relief of mathematics anxiety. Journal for Research in Mathematics Education, 21, 34-46.

Hendel, D. D. (1980). Experimental and affective correlates of math anxiety in adult women. Psychology of Women Quarterly, 5, 219-230.

Hendel, D., \& Davis, S. (1978). Effectiveness of an intervention strategy for reducing mathematics anxiety. Journal of Counseling Psychology, 25, 429-434.

Hunsley, J., \& Flessati, S. L. (1988). Gender and mathematics anxiety: The role of mathrelated experiences and opinions. Anxiety Research, 1, 215-224.

Hyde, J. S., Fennema, E., \& Lamon, S. J. (1990). Gender differences in mathematics performance: A meta-analysis. Psychological Bulletin, 107, 139-155.

Kennedy, L. M., \& Tipps, S. (1990). Guiding children's learning of mathematics (6th ed.). Belmont, CA: Wadsworth.

Lalonde, R. N., \& Gardner, R. C. (1993). Statistics as a second language? A model for predicting performance in psychology students. Canadian Journal of Behavioural Science, 25, 108-125.

Lang, P. J. (1968). Fear reduction and fear behavior: Problems in treating a construct. In J. M. Schlien (Ed.), Research in psychotherapy (Vol. 3, pp. 90-102). Washington, DC: American 
Psychological Association.

Mandler, G., \& Sarason, S. B. (1952). A study of anxiety and learning. Journal of Anxiety and Learning, 47, 166-173.

Marsh, H. W. (1988). The content specificity of math and English anxieties: The high school and beyond study. Anxiety Research, 1, 137-149.

McNeil, D. W., Ries, B. J., \& Turk, C. L. (1995). Behavioral assessment: Self-report, physiology, and overt behavior. In R. A. Heimberg, M. R. Liebowitz, D. A. Hope, \& F. R. Schneier (Eds.), Social phobia: Diagnosis, assessment, and treatment (pp. 202-231). New York: Guilford.

Meece, J. L., Parsons, J. E., Kaczala, , C. M., Goff, S. B., \& Futterman, R. (1982). Sex differences in mathematics achievement: Toward a model of academic choice. Psychological Bulletin, 91, 324-348.

Milgrom, P., Weinstein, P., Kleinknecht, R., \& Getz, T. (1980). Treating fearful dental patients: A patient management handbook. Reston, VA: Reston Publishing Company Inc.

Parsons, J. E., Adler, T. F., \& Kaczala, C. M. (1982). Socialization of achievement attitudes and beliefs: Parental influences. Child Development, 53, 310-321.

Plake, B. S., Ansorge, C. J., Parker, C. S., \& Lowry, S. R. (1982). Effects of item arrangements, knowledge of arrangements, test anxiety and sex on test performance. Journal of Educational Measurement, 19, 49-57,

Plake, B. S., \& Parker, C. S. (1982). The development and validation of a revised version of the Mathematics Anxiety Rating Scale. Educational and Psychological Measurement, 42, 551557.

Plake, B. S., Smith, E. P., \& Damsteegt, D. D. (1981). A validity investigation of achievement anxiety test. Educational and Psychological Measurement, 41, 1215-1222.

Ramirez, O. M., \& Dockweiler, C. J. (1987). Mathematics anxiety: A systematic review. In R. Schwarzer, H. M. Ploeg, \& C. D. Spielberger (Eds.), Advances in test anxiety research (Vol. 5, pp. 157-175). Hillsdale, NJ: Erlbaum Associates.

Richardson, F. C., \& Suinn, R. M. (1972). The Mathematics Rating Scale: Psychometric data. Journal of Counseling Psychology, 19, 551-554. 
Richardson, F. C., \& Woolfolk, R. L. (1980). Mathematics anxiety. In I. Sarason (Ed.), Test anxiety: Theory, research and applications (pp. 271-288). Hillsdale, NJ: Erlbaum.

Robinson, S. E. (1983). Nader versus ETS: Who should we believe? Personnel and Guidance Journal, 61, 260-262.

Rounds, J. B., \& Hendel, D. D. (1980). Measurement and dimensionality of mathematics. Journal of Counseling Psychology, 27, 139-149.

Schneider, W. J., \& Nevid, J. S. (1993). Overcoming math anxiety: A comparison of inoculation training and systematic desensitization. Journal of College Student Development, 34, 283-288.

Smith, K. L., Michael, W. B., \& Hocevar, D. (1990). Performance on creativity measures with examination-taking instructions intended to induce high or low levels of test anxiety. Creativity Research Journal, 3, 265-280.

Spielberger, C. D. (1972a). Anxiety as an emotional state. In C. D. Spielberger (Ed.), Anxiety: Current trends in theory and research (Vol. 1, pp. 23-49). New York: Academic Press.

Spielberger, C. D. (1972b). Conceptual and methodological issues in anxiety research. In C. D. Spielberger (Ed.), Anxiety: Current trends in theory and research (Vol. 2, pp. 481-493). New York: Academic Press.

Spielberger, C. D. (1980). Preliminary professional manual for the Test Anxiety Inventory. Palo Alto, CA: Consulting Psychologists Press.

Spielberger, C. D., Gonzalez, H. P., Taylor, C. J., Algaze, B., \& Anton, W. D. (1978). Examination stress and test anxiety. In C. D. Spielberger \& I. G. Sarason (Eds.), Stress and Anxiety (pp. 167-216). New York: Wiley.

Spielberger, C. D., Gorsuch, R. L., Lushene, R., Vagg, P. R., \& Jacobs, G. A. (1983). Manual for the State-Trait Anxiety Inventory (STAI Form Y). Palo Alto, CA: Consulting Psychologists Press.

Spielberger, C. D., \& Vagg, P. R. (1995). Test anxiety: A transactional process model. In C. D. Spielberger \& P. K. Vagg (Eds.), Test anxiety: Theory, assessment, and treatment (pp. 3-14). Washington, DC: Taylor \& Francis.

Suinn, R. M. (1969). The STABS, a measure of test anxiety for behavior therapy: 
Normative data. Behaviour Research and Therapy, 7, 335-339

Tobias, S., \& Weissbrod, C. (1980). Anxiety and mathematics: An Update. Harvard Educational Review, 50, 63-70.

Watson, D., \& Friend, R. (1969). Measurement of social evaluative anxiety. $\underline{\text { Journal of }}$ Consulting and Clinical Psychology, 33, 448-457.

Yerkes, R. M., \& Dodson, J. D. (1908). The relationship of strength of stimulus to rapidity of habit formation. Journal of Comparative and Neurological Psychology, 18, 459-482. 
Table 1

Variables within Each of Six Hypothesized Clusters of Math Anxious Individuals

\begin{tabular}{|c|c|c|}
\hline$\underline{\text { Cluster } 1}$ & $\underline{\text { Cluster } 3}$ & $\underline{\text { Cluster } 5}$ \\
\hline High test anxiety & High test anxiety & Low test anxiety \\
\hline High evaluation anxiety & High evaluation anxiety & Low evaluation anxiety \\
\hline High trait anxiety & Low trait anxiety & Low trait anxiety \\
\hline Low math performance & Low math performance & Low math performance \\
\hline$\underline{\text { Cluster } 2}$ & $\underline{\text { Cluster } 4}$ & Cluster 6 \\
\hline High test anxiety & High test anxiety & Low test anxiety \\
\hline High evaluation anxiety & High evaluation anxiety & Low evaluation anxiety \\
\hline High trait anxiety & Low trait anxiety & Low trait anxiety \\
\hline High math performance & High math performance & High math performance \\
\hline
\end{tabular}


Table 2

Description of the Four Groupings of Participants

$\underline{\text { First administration }}$

$\underline{\text { Second administration }}$

$\underline{\text { SAT version / Type of Instruction }}$

$\underline{\text { SAT version / Type of Instruction }}$

1. 1995 / stressful

1996 / relaxing

2. 1996 / stressful

1995 / relaxing

3. 1995 / relaxing

1996 / stressful

4. 1996 / relaxing

1995 / stressful 
Table 3

Means, (Standard Deviations), and ANOVA Results for Dependent Variables across Clusters

\begin{tabular}{|c|c|c|c|c|c|}
\hline & \multicolumn{3}{|c|}{ Clusters } & \multirow[b]{2}{*}{$\underline{\mathrm{F}}$} & \multirow[b]{2}{*}{$\mathrm{p}$} \\
\hline & Cluster 1 & Cluster 2 & Cluster 3 & & \\
\hline 1. MARS (Math Anxiety) & $80.7(10.8)$ & $83.6(13.3)$ & $76.8(9.7)$ & 2.8 & .069 \\
\hline 2. FNE (Evaluation Anxiety) & $18.9(7.8)$ & $16.0(8.9)$ & $16.0(8.4)$ & 1.3 & .290 \\
\hline 3. TAI (Test Anxiety) & $58.5(15.8)$ & $54.2(16.0)$ & $53.3(12.5)$ & 1.0 & .361 \\
\hline 4. STAI-Trait (Trait Anxiety) & $50.1(11.0)$ & $49.4(11.5)$ & $45.9(12.4)$ & 1.1 & .350 \\
\hline \multicolumn{6}{|l|}{ 5. STAI-State (State Anxiety } \\
\hline Change; 1995 SAT Version) & ) $-1.4(9.9)$ & $-2.1(11.4)$ & $-2.2(7.3)$ & 1.8 & .166 \\
\hline \multicolumn{6}{|l|}{ 6. STAI-State (State Anxiety } \\
\hline Change; 1996 SAT Version) & $-2.6(8.1)$ & $.6(9.3)$ & $.6(8.9)$ & 1.4 & .251 \\
\hline \multicolumn{6}{|l|}{ 7. SAT Score (1995 Version; } \\
\hline number correct) & $9.3(4.1)$ & $8.7(3.4)$ & $8.9(3.3)$ & .30 & .783 \\
\hline \multicolumn{6}{|l|}{ 8. SAT Score (1996 Version; } \\
\hline number correct) & $10.3(4.1)$ & $8.7(2.7)$ & $10.4(2.6)$ & 3.1 & .048 \\
\hline \multicolumn{6}{|l|}{ 9. SAT Completion Time } \\
\hline (1995 SAT Version) & $25.5^{\mathrm{a}}(4.2)$ & $13.9^{\mathrm{b}}(2.6)$ & $17.4^{\mathrm{c}}(1.8)$ & 123.4 & $<.001$ \\
\hline \multicolumn{6}{|l|}{ 10. SAT Completion Time } \\
\hline (1996 SAT Version) & $24.9^{\mathrm{a}}(6.1)$ & $14.9^{\mathrm{b}}(2.5)$ & $20.5^{\mathrm{c}}(2.5)$ & 53.7 & $<.001$ \\
\hline 11. Age & $21.1^{\mathrm{a}}(5.4)$ & $18.7^{\mathrm{b}}(1.9)$ & $19.6^{\mathrm{a}, \mathrm{b}}(4.0)$ & 3.1 & .048 \\
\hline
\end{tabular}

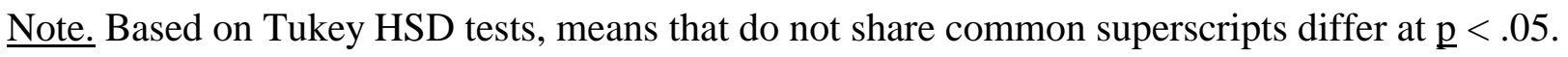


Table 4

$\underline{\text { Pearson Correlations among Dependent Measures used in Cluster Analyses }}$

$\begin{array}{lllllllllll}\text { Dependent Measures } & 1 & 2 & 3 & 4 & 5 & 6 & 7 & 8\end{array}$

\begin{tabular}{|c|c|c|c|c|c|c|c|c|}
\hline \multicolumn{9}{|c|}{ Sample $(\underline{\mathrm{n}}=96)$} \\
\hline $\begin{array}{l}\text { 1. MARS-R } \\
\text { (Math Anxiety) }\end{array}$ & -- & $.31 * *$ & $.21 *$ & .17 & .15 & -.08 & $-.21 *$ & $-.22 *$ \\
\hline $\begin{array}{l}\text { 2. FNE } \\
\text { (Evaluation Anxiety) }\end{array}$ & -- & -- & $.43 * *$ & $.56 * *$ & -.07 & -.1 & -.05 & -.11 \\
\hline $\begin{array}{l}\text { 3. TAI } \\
\text { (Test Anxiety) }\end{array}$ & -- & -- & -- & $.43^{* *}$ & -.1 & .07 & -.14 & -.08 \\
\hline $\begin{array}{l}\text { 4. TAI-Trait } \\
\text { (Trait Anxiety) }\end{array}$ & -- & -- & -- & -- & .12 & -.06 & -.02 & -.08 \\
\hline $\begin{array}{l}\text { 5. STATE95 } \\
\text { (State Anxiety Chang }\end{array}$ & 19 & -- & -- & -- & -- & $-.26 * *$ & -.00 & -.07 \\
\hline $\begin{array}{l}\text { 6. STATE96 } \\
\text { (State Anxiety Change } 1\end{array}$ & 996 & Versior & -- & -- & -- & -- & .09 & .05 \\
\hline $\begin{array}{l}\text { 7. SAT95 } \\
\text { (SAT } 1995 \text { Version) }\end{array}$ & -- & -- & -- & -- & -- & -- & -- & $.60 * *$ \\
\hline $\begin{array}{l}\text { 8. SAT96 } \\
\text { (SAT } 1996 \text { Version) }\end{array}$ & -- & -- & -- & -- & -- & -- & -- & -- \\
\hline
\end{tabular}

Note. $* \underline{p}<.05 . * * \underline{p}<.01$ 
Table 5

Differences between Actual Cluster Solutions

$\begin{array}{lll}\left.\frac{\text { Cluster } 1}{\text { " }} \underline{\mathrm{n}}=30\right) & \underline{\text { Cluster } 2}(\underline{\mathrm{n}}=38) & \underline{\text { Cluster } 3}(\underline{\mathrm{n}}=28) \\ \text { "Goers but Haters" } & \text { "Escapers" } & \\ \end{array}$

\begin{tabular}{|c|c|c|}
\hline & Completion Time for & \\
\hline & $\underline{\text { SAT - } 1995 \text { Version }}$ & \\
\hline$\underline{\mathrm{M}}=25.5$ & $\underline{\mathrm{M}}=13.9$ & $\underline{\mathrm{M}}=17.4$ \\
\hline \multirow[t]{3}{*}{$\underline{(\mathrm{SD}}=4.2)$} & $(\underline{\mathrm{SD}}=2.6)$ & $(\underline{\mathrm{SD}}=1.8)$ \\
\hline & Completion Time for & \\
\hline & $\underline{\text { SAT }-1996 \text { Version }}$ & \\
\hline$\underline{\mathrm{M}}=24.9$ & $\underline{\mathrm{M}}=14.9$ & $\underline{\mathrm{M}}=20.5$ \\
\hline \multirow[t]{2}{*}{$\underline{(\mathrm{SD}}=6.1)$} & $(\underline{\mathrm{SD}}=2.5)$ & $(\underline{\mathrm{SD}}=2.5)$ \\
\hline & $\underline{\text { Age }}$ & \\
\hline$\underline{\mathrm{M}}=21.1$ & $\underline{\mathrm{M}}=18.7$ & $\underline{\mathrm{M}}=19.6$ \\
\hline$\underline{(\mathrm{SD}}=5.4)$ & $(\underline{\mathrm{SD}}=1.9)$ & $(\underline{\mathrm{SD}}=4.0)$ \\
\hline
\end{tabular}

Note. Means for completion times are expressed in minutes.

Means of age are expressed in years. 
Appendix A

Demographics Questionnaire - Part 1

\section{Directions: Please answer the following questions as indicated by writing your answer on this piece of paper.}

1. Your code number for this study

2. Your age

3. How many math courses did you take in high school?

4. How many math courses did you take at the college level?

5. Using the numbers from the list below, indicate the occupations of yourself, your spouse, or significant other (if any), and your parents; if unsure how to categorize, just write a brief description of the job.

_ Your occupation

__ Spouse's or significant other's occupation (if none, write "none")

_ Mother's occupation

Father's occupation

(1) Executive, major professional

(6) Semi-skilled worker

(2) Manager, minor professional

(7) Unskilled worker

(3) Administrator, owner of a small business, semi-professional

(8) Unemployed

(4) Clerical and sales worker

(9) Homemaker

(5) Skilled worker

(10) Student

6. Using the numbers from the list below, indicate how far each of you went in school.

_ Yourself

Spouse or significant other (if none, write "none")

_ Your mother

Your father

(1) Graduate or professional training (degrees obtained)

(2) Partial graduate or professional training

(3) College graduate (degree obtained)

(4) Partial college training (include technical schooling beyond high school) 


\section{Appendix A \\ Demographics Questionnaire - Part 1 Continued}

(5) High school graduate (graduate of technical or trade school)

(6) Partial high school (10th grade through 12th grade)

(7) Partial junior high school (7th grade through 9th grade)

(8) Elementary school (6th grade) 
Appendix B

Demographics Questionnaire - Part 2

\section{Directions: Please indicate your answer by marking the appropriate letter on your} scantron sheet.

1. Gender: $\mathrm{A}=$ Male

$$
\mathrm{B}=\text { Female }
$$

2. Ethnicity: $\mathrm{A}=$ Caucasian

$$
\begin{aligned}
& B=\text { African American } \\
& C=\text { Hispanic } \\
& D=\text { Asian or Pacific Islander } \\
& E=\text { American Indian or Alaskan Native }
\end{aligned}
$$

3. My typical high school math grades were (leave blank if did not take a math course in high school): $\quad \mathrm{A}=\mathrm{A}$ 's

$$
\begin{aligned}
& \mathrm{B}=\mathrm{B} \text { 's } \\
& \mathrm{C}=\mathrm{C}^{\prime} \mathrm{s} \\
& \mathrm{D}=\mathrm{D} \text { 's } \\
& \mathrm{E}=\mathrm{F}^{\prime} \mathrm{s}
\end{aligned}
$$

4. In high school, I was typically enrolled in the following type of math courses:

$$
\begin{aligned}
& A=\text { Standard } \\
& B=\text { Advanced } \\
& C=\text { Remedial } \\
& D=\text { None or does not apply }
\end{aligned}
$$

5. My typical college math grades have been (leave blank if you have not taken a college level math course):

$$
\begin{aligned}
& \mathrm{A}=\mathrm{A}^{\prime} \mathrm{s} \\
& \mathrm{B}=\mathrm{B} \text { 's } \\
& \mathrm{C}=\mathrm{C}^{\prime} \mathrm{s} \\
& \mathrm{D}=\mathrm{D}{ }^{\prime} \mathrm{s} \\
& \mathrm{E}=\mathrm{F}^{\prime} \mathrm{s}
\end{aligned}
$$




\section{Appendix B}

\section{Demographics Questionnaire - Part 2 Continued}

6. In college, I have typically been enrolled in the following type of math courses:

$$
\begin{aligned}
& \mathrm{A}=\text { Standard } \\
& \mathrm{B}=\text { Advanced } \\
& \mathrm{C}=\text { Remedial } \\
& \mathrm{D}=\text { None or does not apply }
\end{aligned}
$$

\section{Have you taken any courses in each of the following areas?}

7. Algebra?

$$
\begin{aligned}
& A=\text { Yes } \\
& B=\text { No }
\end{aligned}
$$

8. Geometry?

$$
\begin{aligned}
& A=\text { Yes } \\
& B=\text { No }
\end{aligned}
$$

9. Pre-Calculus?

$$
\begin{aligned}
& A=\text { Yes } \\
& B=\text { No }
\end{aligned}
$$

10. Calculus?

$$
\begin{aligned}
& A=\text { Yes } \\
& B=\text { No }
\end{aligned}
$$

11. Statistics?

$$
\begin{aligned}
& A=\text { Yes } \\
& B=\text { No }
\end{aligned}
$$

12. Trigonometry?

$$
\begin{aligned}
& A=\text { Yes } \\
& B=\text { No }
\end{aligned}
$$


Appendix C

Stressful Instructions

You will have exactly 30 minutes to complete this math subtest of the SAT. As you probably know, the SAT is the Scholastic Achievement Test. You will be taking one of the math subtests from an actual SAT that was administered in 1995 or 1996. Please work as quickly and accurately as possible. The answers will be strictly graded. Each answer must be the absolute best you can give. You, cannot, under any circumstances go back and add to or change answers once time has been called. You must work under strict time limits. Furthermore, your performance will be scrutinized closely to determine your mathematical abilities.

Before beginning the SAT, however, please complete the STAI-State and follow the instructions at the top of it. After you finish it, please stop and wait for instructions before beginning work on the SAT. You can begin now. 
Appendix D

\section{Relaxing Instructions}

You will have as much time as you wish to complete this math subtest of the SAT. As you probably know, the SAT is the Scholastic Achievement Test. You will be taking one of the math subtests from an actual SAT that was administered in 1995 or 1996 . You have plenty of time to work on this test so you can have fun, relax, and enjoy it. Given the amount of time you have, this should move along smoothly, and at a comfortable rate. Furthermore, your performance will not be used to determine your mathematical abilities, although I encourage you to answer the questions accurately and to finish the test. Because you have plenty of time, you will feel less stressed, and will probably answer the questions more accurately. Have fun and good luck.

Before beginning the SAT, however, please complete the STAI-State and follow the instructions at the top of it. After you finish it, please stop and wait for instructions before beginning work on the SAT. You can begin now. 


\section{CURRICULUM VITAE}

\section{BIOGRAPHICAL}

Name

Business Address

Telephone

Email

1994

1995-present

1995-present

1996-7

1997-8
Aline Rabalais

West Virginia University

Department of Psychology

P.O. Box 6040

Morgantown, WV 26505

(304) 293-2001 ext. 847

arabalai@wvu.edu

\section{EDUCATION}

Bachelor of Arts in Psychology, University of Houston

Minor in English

Clinical Psychology Ph.D. Program, West Virginia University

\section{PROFESSIONAL EXPERIENCES}

Therapist

Quin Curtis Center for Psychological Services:

Graduate Training Clinic

West Virginia University

Department of Psychology

William Sharpe Hospital (state psychiatric facility),

Weston, WV

Veterans Administration

Clarksburg, West Virginia 


\section{MEMBERSHIP IN PROFESSIONAL ORGANIZATIONS}

Division 45 of the American Psychological Association:

Society for the Psychological Study of Ethnic Minority Issues)

Division 12 of the American Psychological Association (i.e., Clinical Psychology)

Association for the Advancement of Behavior Therapy (AABT)

\section{PUBLICATIONS}

Fox, M. L., Masia, C. L., McNeil, D. W., \& Rabalais, A. E. (1996). Practice Effects with Social and Neutral Stroop Words. Poster presented at the Association for Advancement of Behavior Therapy, New York, NY.

Lau, A., Rabalais, A., Mullen, K., Annan, S., Ryan, K., Myers, M., Gilbert, T., Minami, T., Tolka, B., Scotti, J., \& Morris, T (1997). An investigation of malingering in response to a community-wide industrial accident. Poster presented at the Association for Advancement of Behavior Therapy, Miami, FL.

McNeil, D. W., Rabalais, A. E., Porter, C. A., \& Fox, M. L. (1996). Math Anxiety in Native American College Students. Poster presented at the Association for Advancement of Behavior Therapy, New York, NY.

McNeil, D. W., Zvolensky, M. J., Porter, C. A., Rabalais, A., McPheron-Alex, T., \& Kee, Marvin (in press). Anxiety Disorders in American Indians and Alaska Natives: Identification and Intervention. Indian Health Service Care Provider.

Venable, R., \& Rabalais, A. (1997). Direct therapeutic exposure for civil war-related PTSD in a missionary. Poster presented at the Association for Advancement of Behavior Therapy, Miami, FL.

\section{PRESENTATIONS}

Rabalais, A. (1997). Motor vehicle accidents: A common and traumatic event. Paper presented at the annual meeting of the West Virginia Psychological Association, Flatwoods, WV.

Venable, R., \& Rabalais, A. (1997). Direct Therapeutic Exposure: Application with a civilian exposed to civil war. Paper presented at the annual meeting of the West Virginia Psychological Association, Flatwoods, WV. 